\title{
Towards Reliability Centred Maintenance of Wind Turbines
}

\author{
David McMillan \\ Institute for Energy \& Environment \\ University of Strathclyde \\ Glasgow, UK \\ dmcmillan@eee.strath.ac.uk
}

\author{
Graham W. Ault \\ Institute for Energy \& Environment \\ University of Strathclyde \\ Glasgow, UK
}

\begin{abstract}
Reliability centred maintenance applied to a fleet of wind turbines is presented in this paper. The key components and failure modes are identified via analysis of maintenance records. Corrective actions which an operator can take to mitigate such failures are discussed, together with implementation issues. By developing a robust set of RCM tools, wind farm operators can better quantify and minimise operational expenditure of wind farm fleets.
\end{abstract}

Keywords-wind farm; Wind Turbine, Reliability Centred Maintenance, Risk.

\section{INTRODUCTION}

Control of operation and maintenance (O\&M) cost is an area of growing interest to wind farm operators, as groups of assets come to the end of equipment manufacturers warranty agreements. Reliability centred maintenance (RCM) has very successful previous applications in thermal plant, and here is applied to wind turbines. By identifying key components and quantifying risk, maintenance effort can be focused on appropriate areas thus lowering O\&M spend in the longer term.

\section{PREVIOUS WORK AND LITERATURE REVIEW}

\section{A. $\quad$ RCM and Wind Plant}

Ribrant and Bertling [1] carried out a study which provided comprehensive failure rate and downtime data by WT subassembly. The database comprised many different WT models and manufacturers. This paper also contains a study of gearbox failure modes, including repair and replacement statistics. Such detailed failure information provides an important and rare insight into wind farm operational issues.

Rademakers et al. [2] looked at a structural breakdown of parts within a wind turbine and discussed failure detection methods such as inspection and condition monitoring. A fault tree analysis was carried out for the component parts such as rotor, nacelle and tower. Via this detailed analysis a flaw in the design of the studied turbine was detected and the authors suggested more sensor redundancy to cut down the risk of failure, showing the value of such an approach. Similar studies were carried out by Michos et al. [3] with the focus on safety issues. More recently ArabianHoseynabadi et al. [4] describe the failure modes and effects analysis (FMEA) approach and apply it to a set of WT reliability data.

Andrawus et al. [5] examined RCM as part of maintenance modeling. Data from operational wind farms are used to populate the model in order to establish an optimal maintenance policy. Similar studies can be found in $[6,7,8]$ which deal with different aspects of the problem such as specific component parts or the effect of seasonal weather patterns.

This paper contains a real application of RCM methods to a fleet of operational wind farms. By analyzing operational maintenance data, important failure modes can be highlighted and action taken to mitigate them. Such methods are under-utilised in the wind industry at present.

\section{B. RCM Literature}

Several excellent RCM resources are available, such as $[9,10]$. A comprehensive and transparent case study, where RCM is applied to gas turbine power plant, can be found in [11] - in this case the authors importantly measure the plant performance improvement after 1 iteration of the RCM process. Such performance benchmarking is crucial in the longer term to justify the resource allocation to RCM, as well as any extra labour or material cost incurred by mitigation methods such as condition monitoring.

\section{RCM PROCESS}

The RCM process can be broken down into the following steps $[9,10,11]$, which are adopted in this paper:

Step 1 - System selection and information collection.

- Collect data

- Define system boundaries

Step 2 - Develop Understanding of System

- Define sub systems

- Functional Tree 
Step 3 - Define system functions and functional failures

- FMECA

- data processing

- detailed risk analysis (main result)

Step 4 - Task selection (feedback)

- Identify components for more maintenance effort

- 'prioritisation' of maintenance based on criticality

- Is condition monitoring justified?

\section{A. Data Sources}

The main source of data used in the analysis was a set of maintenance records used as part of a maintenance management system [12]. Table I illustrates the data set available, where $\# W T_{n}$ is the number of wind turbines at site $\mathrm{n}$ and $\Delta t_{n}$ is the time in years covering the maintenance record from that site. WT models A and B are of similar design and have a large majority of common components.

It can be seen from the data start and data end fields in Table I, parallel streams of data are available from more than one site for some periods, whereas for other time periods there is no coverage.

TABLE I

MAINTENANCE DATA SUMMARY

\begin{tabular}{c|ccccccc}
\hline Site & MW & Model & $\# W T_{n}$ & data start & data end & months & $\Delta t_{n}($ years $)$ \\
\hline Site 1 & 36.8 & A & 16 & $11 / 2008$ & $02 / 2011$ & 28 & 2.33 \\
Site 2 & 119.6 & B & 52 & $11 / 2007$ & $02 / 2011$ & 40 & 3.33 \\
Site 3 & 36.8 & A & 16 & $05 / 2008$ & $11 / 2010$ & 31 & 2.83 \\
\hline
\end{tabular}

In order to calculate annual occurrence and failure rates $(\lambda)$, the total number of WT operational years $W T \Delta t_{\text {total }}$ must be deduced using equation 1 . This is calculated in Table I as 255.72 WT-years equivalent. This figure is used to calculate failure rates (2) for subcomponents common to WT models A and B. Where components are exclusive to Model A or B, then $W T \Delta t_{A}=82.56$ (WT-years equivalent) and $W T \Delta t_{B}=$ 173.16 .

$$
\begin{array}{r}
W T \Delta t_{\text {total }}=\sum_{n=1}^{3} \Delta t_{n} \times \# W T_{n} \\
\lambda_{F M \#}=\frac{F r e q_{F M \#}}{W T \Delta t_{\text {total }}}
\end{array}
$$

\section{B. System Description}

The system under study is a Danish concept multi-MW onshore wind turbine. Analysis of the system was limited to the wind turbine asset and switchgear - inter array transmission was not included. Asset sub-groups were defined via an existing wind farm operators asset structure and were allocated a failure mode number (FM\#), as shown in Table II.

\section{Develop Understanding of System under Study}

Original equipment manufacturers' (OEM) maintenance and user manuals were used to develop a good understanding of the WT sub-systems in Table II. This was augmented by expert knowledge of wind farm site operators. Together with maintenance records, a comprehensive system picture was built up. The resultant functional tree for the WT system is omitted for brevity.

\section{FMECA}

A FMECA of model A and B turbines was carried out independently and prior to the work in this paper. The findings are shown in Table III where the risk priority number (RPN) is between 1 (low risk) and 5 (very high). The work presented in this paper builds on this previous work by providing a higher level of detail in terms of failure modes experienced and quantification of rates of occurrence, as well as economic impact.

TABLE II

ASSET GROUP FAILURE MODE NUMBER

\begin{tabular}{c|c}
\multicolumn{2}{c}{ ASSET GROUP FAILURE MODE NUMBER } \\
\hline Asset group & FM \# \\
\hline overall asset & 0 \\
blade system & 100 \\
parking brake & 200 \\
controller & 300 \\
gearbox & 400 \\
generator & 500 \\
hub & 600 \\
hydraulics & 700 \\
nacelle & 800 \\
over speed system & 900 \\
pitch & 1000 \\
power factor correction (PFC) & 1100 \\
tower & 1200 \\
transmission & 1300 \\
yaw & 1400 \\
measurement (sensors etc) & 1500 \\
HV system & 1600 \\
switchgear & 1700 \\
\hline
\end{tabular}


TABLE III

\begin{tabular}{c|c} 
FMECA OUTPUT - RISK RANKING \\
Asset & RPN \\
\hline Gearbox & 4 \\
Transmission & 4 \\
Slip ring & 2 \\
Hydraulic System & 2 \\
Anemometry & 2 \\
$\alpha$-control panel & 2 \\
$\mu$-control panel & 2 \\
Generator & 2 \\
Tower & 2 \\
Pitch & 2 \\
\hline
\end{tabular}

IV.

\section{MAIN RESULTS}

\section{A. Data Processing}

The data summarised in Table I were processed and categorized according to fault type, asset category, turbine model, date stamp and type of maintenance performed. Downtime information was also available for some failures. The main issue when carrying out the data processing was a lack of standardization in terms of fault reporting. In some cases information was comprehensive, and in others, highly sparse. Lack of standardization of component nomenclature was particularly arduous as this meant the data processing could not be automated.

Another issue is the definition of a fault. In some cases faults can be re-set remotely - does this constitute a maintenance entry? Likewise, inspections may be either planned or in reaction to a perceived fault or abnormal operating condition. The maintenance records had to be carefully interpreted in order that mistakes were not made with failure classifications.

Figure 1 shows the occurrence rate of maintenance entries by asset category. These include all entries: inspections (planned and reactive), fault investigations, as well as repairs, replacements and retrofits. Because of this, some of the occurrence rates in Figure 1 are surprisingly large. Gearbox and transmission asset groups in particular are in some cases inflated by early-life inspection regimes to mitigate possible serial defects. Nacelle asset group occurrence rates stem mainly from anemometry. The controller asset group is by far the biggest contributor.

Table IV shows the failure rate per annum, $\lambda$, of the most frequently occurring failure modes - that is component failures which require an unscheduled maintenance visit. Remote resets, scheduled inspections, and retrofits are not included. For a more comprehensive analysis, impact of failures should also be included, since the failure modes in Table IV may not be among the most problematic from a maintenance viewpoint.

TABLE IV

FAILURE MODES RANKED By FAILURE RATE

\begin{tabular}{c|cc}
\multicolumn{4}{c}{ FAILURE MODES RANKED BY FAILURE RATE } \\
\hline Failure Mode & FM \# & $\lambda$ \\
\hline$\mu$-panel cooling system pressure error & 309.3 & 0.315 \\
Capacitor bank failure & 1102.1 & 0.300 \\
$\mu$-panel Grid inverter trip & 309.01 & 0.291 \\
s-panel yaw converter error & 314.6 & 0.266 \\
$\alpha$-panel - trip coil fault & 301.3 & 0.125 \\
switching module replacement & 1106 & 0.116 \\
Wind vane replace & 801.9 & 0.094 \\
ऽ-panel frequency converter fault & 312 & 0.085 \\
$\mu$-panel cooling system fault & 309 & 0.085 \\
Anemometer cup type replace & 801.2 & 0.082 \\
\hline
\end{tabular}

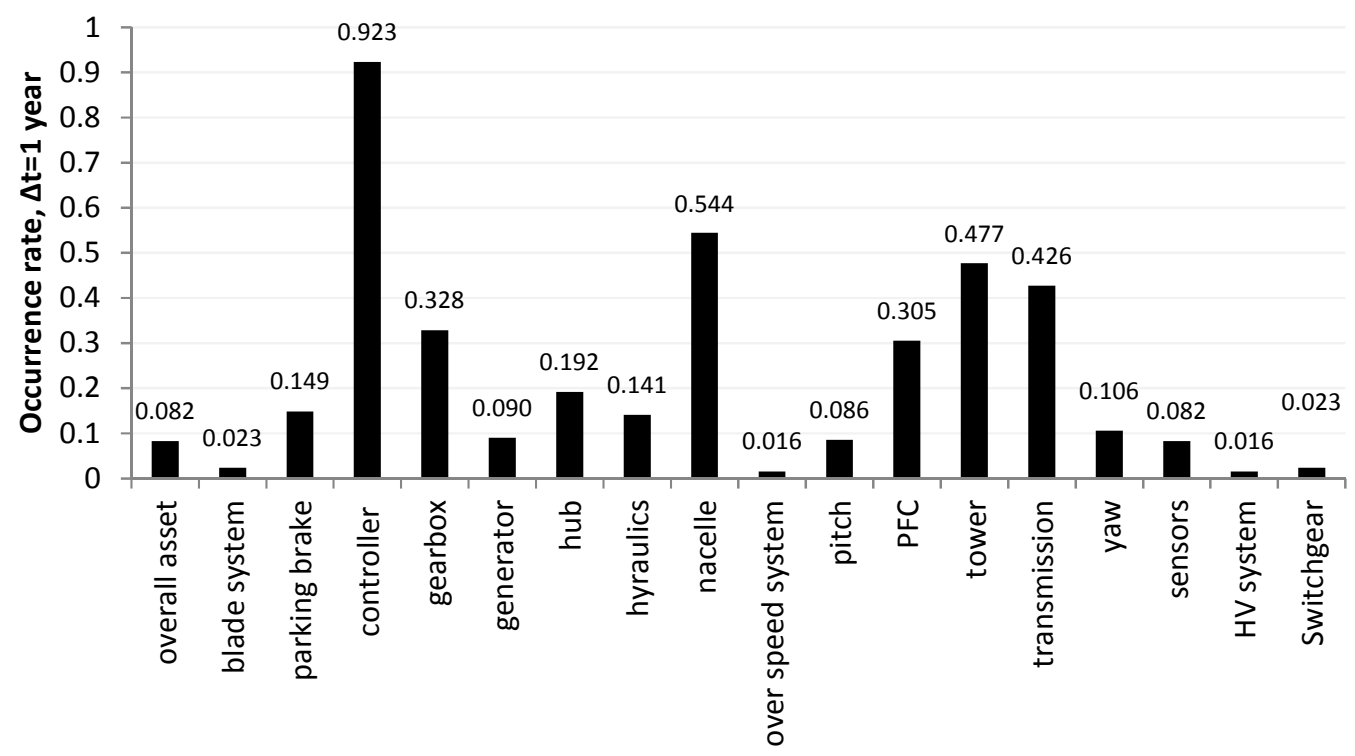

Fig 1. Annual occurrence rate by asset group. 


\section{B. Risk Analysis}

The failure rates in Table IV were calculated for all failure modes in the database. Costs were extracted from three sources. Component costs were obtained from an OEM component spares list. Cranage (hire rates of $£ 13 \mathrm{k}$ 'call out' and $£ 6 \mathrm{k}$ per individual day of hire of $500 \mathrm{t}$ crane, suitable of hub heights of less than $85 \mathrm{~m}$ ) and external labour costs $(£ 80 / \mathrm{Hr})$ were obtained from a wind farm operator. Finally lost revenue was calculated on the basis of a $27 \%$ capacity factor, $2 \mathrm{MW}$ rating $\left(R_{W T}\right)$ and production credit of $£ 76 / \mathrm{MWh}$. Downtimes were extracted from the database where possible, and utility experience used to make estimates of downtime where the database information were sparse. The resultant cost class $\left(C_{\text {class }}\right)$ ranges are summarized in Table V. Each failure mode was classified according to its cost class. Note that lower range values in Table $\mathrm{V}$ have been used in the cases presented here.

Table VI plots the top 10 failure modes by risk level. The quantities - including annual cost of maintenance per wind turbine $\left(C M_{W T}\right)$ and annual cost of maintenance per MW $\left(C M_{M W}\right)$ - were calculated using equations $(3)-(6)$.

$$
\begin{gathered}
\text { Risk }=\lambda_{F M \#} \cdot C_{\text {class }} \\
\text { Approx. cost }=\text { Freq } \cdot F M \#_{\text {. }} \cdot C_{\text {class }} \\
C M_{W T}=\frac{\text { total spend for all FM\# }}{W T \Delta t_{\text {total }}} \\
C M_{M W}=\frac{C M_{W T}}{R_{W T}}
\end{gathered}
$$

These quantitative results align well with qualitative FMECA studies shown earlier in Table III. The top 3 high risk set of failures are further examined to establish what actions can be taken to mitigate these key failure modes.

\section{Corrective Actions}

Feeding the results of RCM analysis back to decision making is perhaps the least well defined area of RCM. Indeed Smith and Hinchcliffe [9] state that "RCM methodology focuses only on what task should be done... [maintenance] intervals are derived from separate analyses".

In practice there are several practical actions a wind farm operator can explore in order to minimise operational risk. For the cracked gearbox failure mode, $95 \%$ of the cost is tied up in component replacement and cranage. Cranage costs could be reduced by good planning of replacement actions, thus avoiding multiple 'call out' cranage rates.

TABLE V

\begin{tabular}{c|c}
\multicolumn{2}{c}{ COST RANGES FOR FAILURES } \\
\hline Class & Cost Class $\left(\mathrm{C}_{\text {class }}\right) £$ \\
\hline A & $300,000+$ \\
B & $100,000-300,000$ \\
C & $50,000-100,000$ \\
D & $10,000-50,000$ \\
E & $5,000-10,000$ \\
F & $1,000-5,000$ \\
G & $500-1,000$ \\
H & $100-500$ \\
\hline
\end{tabular}

TABLE VI

FAILURE MODES RANKED BY RISK

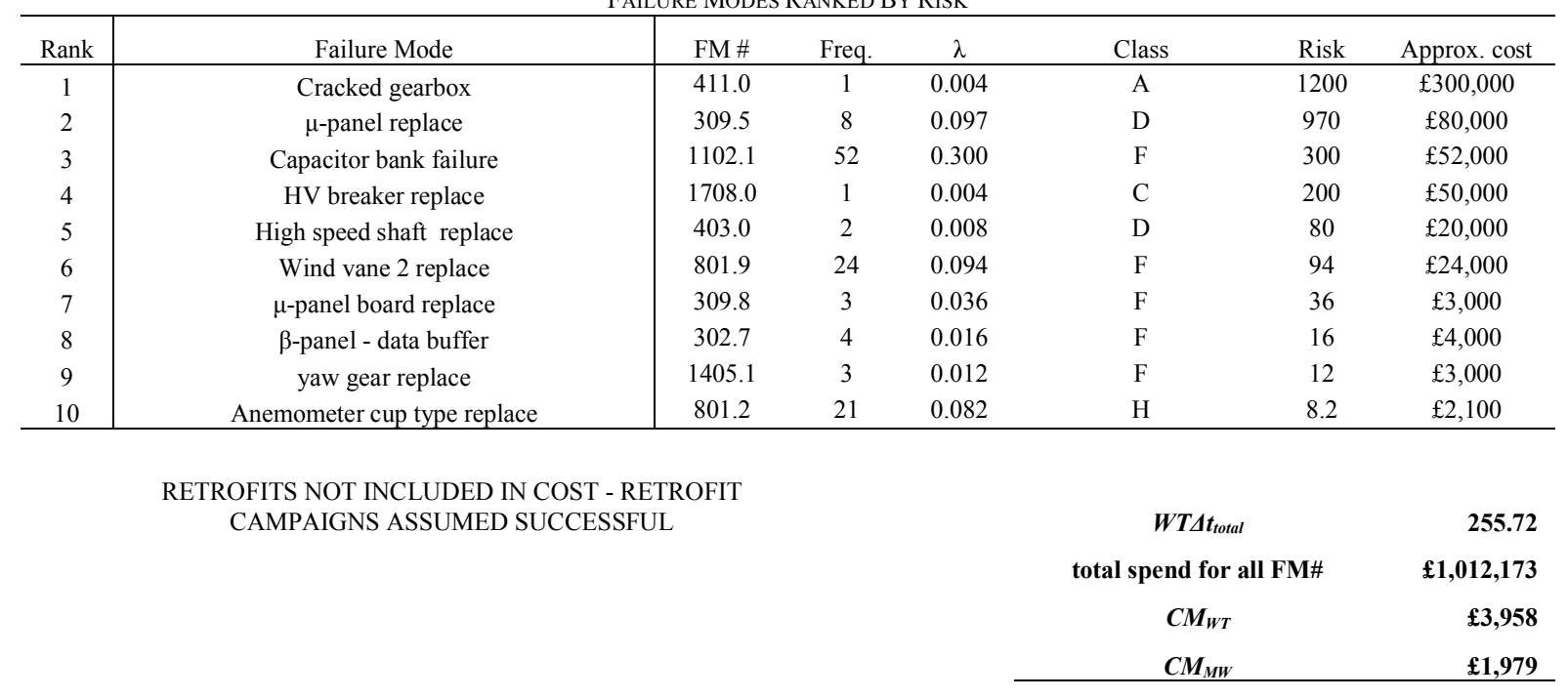


More accurate measures of condition will help operators to plan gearbox replacements in an improved manner. Use of borescopes for improved inspection, and offline oil analysis are two tools which have been used in the aviation industry and can be used on wind turbine gearboxes. The high risk nature of gearbox failure modes as shown in Table VI justifies the cost of these outlays (capital cost of borescope is $\sim £ 25 \mathrm{k}$, and an oil analysis test can be done for as little as $£ 10$ per sample).

The control panel failures shown in Table VI have subsequently been traced to moisture sensitivity and handling issues at the supplier end. This failure can be controlled via improved handling and testing of electronic subassemblies.

Capacitor bank failures are problematic in the sense that they can have secondary effects which increase the cost impact. Additionally Table VI shows that the failure rate is high and should be reduced. This could be achieved either by engaging the OEM to control quality, or sourcing parts from a different supplier. Furthermore the containment of individual capacitors could be improved, in order to stop secondary failures occurring - this would be a feedback to design.

\section{CONCLUSIONS}

The following general observations are made based on the work in this paper.

\section{A. Rigorous Data Entry}

Data entry into the maintenance database was of variable quality. In some cases the records were very complete. In other cases, records had omitted information such as date stamps, turbine number, and corrective action taken. Since the intention is to use the maintenance records as a retrospective source of failure information (to calibrate bathtub curves etc.), use of the database will have to become more rigorous.

\section{B. Fault Reporting Standardisation}

Nomenclature for component failures did not appear to be fully standardized despite the asset group data structure. In many cases failures were placed in the wrong asset category or the component was referred to using shorthand notation of some kind. This made retrospective analysis of failures more difficult. For fleet-wide analysis, nomenclature for components \& failure modes should be standardised and used across all sites. These issues are discussed further in [13].

\section{Calibration of Reliability Curve}

One of the long term aims was to examine the relationship between failures and time, to examine if failures were increasing or decreasing over time (perhaps adhering to a 'bathtub' or other characteristic reliability curve [14]). Because of the relatively short data set used, it has not been possible to do this. However it will be possible to track performance in the future using a standardised database. The database can be periodically updated (on a quarterly or biannual basis) to chart the reliability performance of individual turbine, site or fleet over time.

\section{Value of Good Data}

The standardisation and data entry issues touch on the wider question of "value of data". Since better information capture involves time and resource, it could be questioned whether or not the extra effort is worthwhile from a cost/benefit viewpoint. It would be beneficial to quantify the value of good data in terms of what it can provide in reduction of operational expenditure. It is essential that future performance improvements enabled by access to good data and initiated by application of RCM tools is measured to provide quantifiable evidence that such a process is economically beneficial [11].

The following specific conclusions are drawn:

- Gearbox failures continue to dominate operational risk in wind turbines

This brings into sharp focus the need for design robustness, supplier quality control, and in the longer term, cost effective condition monitoring [15]. Factors currently undermining the economic case for online condition monitoring (particularly vibration monitoring) such as false positives and poor fault diagnosis accuracy, will have to be resolved. A large amount of work needs to be done in extracting meaningful information from existing online condition measurements [16]. Until such techniques are developed further, onshore wind farm operators are likely to favour offline oil analysis as discussed in Section IV C, and visual inspections carried out as part of scheduled maintenance.

- Rate of occurrence and impact of lower risk failures will increase in the offshore environment

Table IV showed that some of the most frequently occurring failures are measurement devices, whose good function is crucial to turbine control and operation. The rate of occurrence of such failures will increase in offshore wind farms due to the more hostile maritime environment. The impact of failure will also substantially increase due to lost production, weather constraints etc. The risk attributed to each failure is therefore very specific to the characteristics of the operating environment. The significance of such failures will be increased offshore - in this case, increased maintenance effort may be impractical. From the design side, functional redundancy could increase to compensate (e.g. multiple anemometers, sensors) however this may not 
be economically viable. Alternatively a simpler, more robust design could be pursued, though in some cases designing components out of a WT can increase the capital cost and undermine the economic case for adoption of those designs [17]. On the operational side, a highly refined system of condition monitoring and maintenance management, similar to systems in the aviation sector, will have to be rolled out.

\section{ACKNOWLEDGMENT}

The input of Dr. Max Parker is gratefully acknowledged.

\section{REFERENCES}

[1] J. Ribrant and L. Bertling, "Survey of Failures in Wind Power Systems with Focus on Swedish Wind Power Plants During 19972005", IEEE Trans. Energy Conversion, vol. 22, no. 1, pp. 167-173, March 2007

[2] L.W.M.M. Rademakers, A.J. Seebregts, B.A. Van den Horn, J.N.T. Jehee, and B.M. Blok, "Methodology for Probabilistic Safety Assessment of Wind Turbines" 1993, ECN-C--93-010

[3] D. Michos, E. Dialynas, and P. Vionis, "Reliability and safety assessment of wind turbines control and protection systems", Wind Engineering, 2002, vol. 26, no. 6, p 359-69.

[4] H. Arabian-Hoseynabadi, H. Oraee, P.J. Tavner, "Failure Modes and Effects Analysis (FMEA) for wind turbines", Electrical Power and Energy Systems vol. 32 (2010) 817-824

[5] J. A. Andrawus, J. Watson, M. Kishk, and A. Adam, "The selection of a suitable maintenance strategy for wind turbines," Wind Eng., vol. 30, no. 6, pp. 471-486, 2006

[6] D. McMillan and G.W. Ault, "Quantification of Condition Monitoring Benefit for Onshore Wind Turbines: Sensitivity to Operational Parameters", IET Renewable Power Generation, vol. 2, no. 1, pp 60-72, March 2008

[7] F. Besnard and L. Bertling, "An Approach for Condition-Based Maintenance Optimization Applied to Wind Turbine Blades", IEEE Transactions on Sustainable Energy, vol. 1, no. 2, p 77-83, July 2010

[8] E. Byon, L. Ntaimo and Y. Ding, "Optimal maintenance strategies for wind turbine systems under stochastic weather conditions" IEEE transactions on reliability vol. 59 no. 2 p.393 -404 June 2010

[9] A.M. Smith and G.R. Hinchcliffe, "RCM - Gateway to world class maintenance" Elsevier 2004

[10] J. Moubray, "Reliability-Centered Maintenance", New York: Industrial Press Inc., 1992.

[11] F. J. Guevara Carazas and G. F. Martha de Souza, "Availability Analysis of Gas Turbines Used in Power Plants", Int. J. of Thermodynamics, vol. 12, no. 1, pp. 28-37, March 2009

[12] MAXIMO http://www01.ibm.com/software/tivoli/products/maximo-assetmgmt/

[13] K. Fischer, F. Besnard and L. Bertling, "A Limited-Scope Reliability-Centred Maintenance Analysis of Wind Turbines" EWEA 2011, 14-17 March 2011, Brussels, Belgium

[14] U. Hjorth, "A reliability distribution with increasing, decreasing, constant and bathtub-shaped failure rates" Technometrics, vol. 22 no. 1, p 99-107, February 1980

[15] W. Yang, P.J. Tavner, C.J. Crabtree and M. Wilkinson, "CostEffective Condition Monitoring for Wind Turbines", IEEE Transactions on Industrial Electronics, vol. 57 no. 1, p 263-271 Jan 2010

[16] C. S. Gray and S.J. Watson, "Physics of Failure approach to wind turbine condition based maintenance", Wind Energy, vol. 13, no. 5, p 395-405, July 2010
[17] D. McMillan and G.W. Ault, "Techno-Economic Comparison of Operational Aspects for Direct Drive and Gearbox-Driven Wind Turbines", IEEE Transactions on Energy Conversion, vol.25 no.1 , p. 191-198 